\title{
A Química de Quase Tudo
}

Andy Brunning

Andy Brunning (Químico e Educador, Cambridge, UK) é o autor do blogue Compound Interest. As infografias deste blogue tornaram-se virais na internet e em 2008 o blogue ganhou um prémio da Association of British Science Writers' Dr. Katharine Giles Science. Atualmente as infografias são feitas com o patrocínio da Chemical \& Engineering News, uma revista semanal da Sociedade Americana de Química. Os temas abordados são muito diversos, e se ainda não conhecem a exploração é obrigatória, apenas por curiosidade científica ou como recurso educativo.

Veja mais em compoundchem.com.

$>$

Vasco Bonifácio

vasco.bonifacio@tecnico.ulisboa.pt

TOXINS IN FRUITS AND VEGETABLES

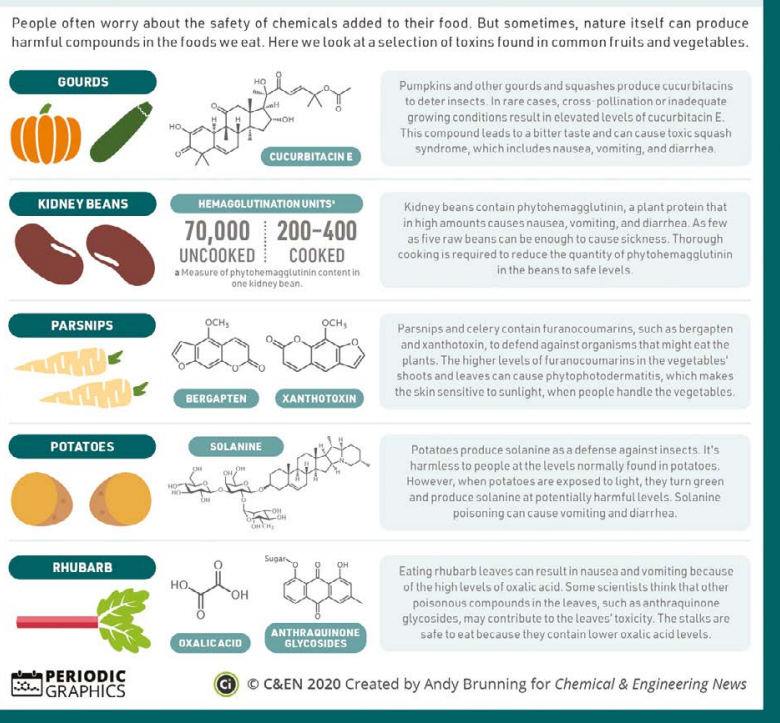

Toxinas em frutos e vegetais: compoundchem.com/2020/12/10/natural-toxins.

\section{Jogar com Mecanismos?}

A Alchemie lançou uma aplicação que permite exercitar os nossos conhecimentos sobre mecanismos de reações químicas. Os desafios são apresentados sob a forma de jogos. Existem vários níveis e alguns são gratuitos. Contudo, para experimentar reações com um nível mais avançado (ex. substituição nucleofílica ou reações de eliminação), é necessário fazer um pagamento (cerca de 8 euros para um período de utilização de 6 meses). Para além da aplicação para telemóvel, Mechanism by Alchemie - Organic Chemistry, é possível usar a versão online para computador. Em ambos os casos é necessário um registo de utilizador. A química orgânica nunca foi tão divertida!

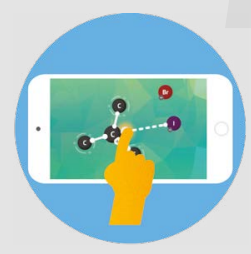

Mechanism by Alchemie - Organic Chemistry

Veja mais em alchem.ie/mechanisms.

$>$

Vasco Bonifácio

vasco.bonifacio@tecnico.ulisboa.pt 